\title{
The SAVE Metaprotocol for Behavior Analysis. An integrative proposal
}

DOI: $10.46932 /$ sfjdv2n2-202

Received in: March 1st, 2021.

Accepted in: May 30th, 2021.

\author{
Rafael M. López Pérez \\ Behavior \& Law Research Foundation, Madrid, Spain \\ E-mail: rlopez@behaviorandlaw.com
}

\section{INTRODUCTION}

We present the System for Analysis of Validity in Evaluation (SAVE), as a potentially useful method for professionals in the field of Legal Psychology and other Forensic Sciences, understood as any discipline that integrates formal aspects from the forensic, behavioral and legal sciences, with a purely applied orientation.

According to Muñoz, et al. (2011), "The great challenge of current Forensic Psychology, from a technical point of view, is in two areas: a) the creation of assessment instruments and methods appropriate to the context of forensic exploration (that are able to circumvent the defensive and manipulative attitude of the examinees while maintaining high parameters of reliability and validity and the object of the same (that allow psycho-legal inferences); and b) consolidate technical criteria based on empirical evidence to support their expert considerations."

"Method" comes from the Latin methodus and this from the Greek, $\mu \varepsilon \dot{\theta}$ o $\delta$ o, meaning, "the way to follow", the steps to be taken to carry out something, the procedure or protocol. It refers both to a properly structured, organized, and systematic way to reach a purpose or result and to the way of proceeding, thinking, acting or behaving, expertise or habit that each one has and observes. Also, the work of art, specialty, or science; for example, in philosophy, the method is the process followed in a study to find the truth and teach it. The interview and other diverse research techniques would not be - in this sense - a method, but only devices, tools of the method, and this, a process used in a theoretical framework (Nateras González, 2005), as occurs with the clinical method (Ilizástegui \& Rodríguez, 1990).

That is the objective of SAVE, to be the method for an orderly, flexible, logical, and adapted to each area application of the most appropriate techniques and tools for the evaluation to be performed. Combining different points of view and structuring what, in many cases, is performed today individually and intuitively (Domínguez-Muñoz, et al., 2017a; Muñoz, 2013). As a Metaprotocol, it integrates and locates various tools previously based on empirical evidence and validated for independent use, from SVA to TOMM to indirect personality profiling. 
Its application is being initiated in diverse but related fields such as forensic (Domínguez-Muñoz, et al., 2018) or evaluative medicine (Domínguez-Muñoz, et al., 2017b), criminal behavior analysis, expert psychology, insurance fraud, etc. They have in common with Forensic Psychology the high frequency of deception "phenomena that take on special relevance in the forensic context" (Muñoz, 2013).

Therefore, we present SAVE in this area where professionals and experts from many fields of knowledge can access, review, question and criticize the proposed method, to make it as useful as possible in the daily practice of those who consider its use in some of the areas of Forensic Sciences; specifically, in Legal Psychology, especially in our understanding, Forensic Psychology, Criminal Psychology, Testimony and Criminal Psychology (Muñoz, et al., 2011).

\section{THE SAVE METAPROTOCOL}

A metaprotocol conceptual framework designed by the Institute for Anti-Fraud Conduct Analysis (IACA) of the Behavior and Law University Foundation is presented for its orderly and structured application; the System for Analysis of Validity in Evaluation or SAVE (Domínguez-Muñoz, et al, 2018).

Its application begins with a legal approach; the factual assumption that gives rise to the investigation of the case. Then, the scientific-technical phase begins, and a hypothesis is proposed prior to the validity analysis itself, which will lead to some results, with which conclusions will be reached with respect to the initial factual assumption, for or against.

It would be useful for the evaluation of validity in various fields such as the study of the credibility of criminological-criminal statements (testimonials, investigative interviews), of fraud in its various environments, including malingering in the medico-legal field, etc. Validity in SAVE is understood in the sense of firmness, consistency, and legal value. Starting from a hypothesis, which in general would always be the authenticity or honesty of the case, the evaluation would begin in an open, friendly, collaborative, and respectful attitude. It consists, in its most basic version, of a triple filter.

- Verisimilitude (Internal Coherence): It is based on verbal content analysis protocols; Statement Validity Assessment (SVA), Reality Monitoring (RM), analysis of the structure of the statement, linguistic, etc. (V1)

- Veracity (Congruence): Integrated analysis of Verbal Behavior (VB) and Non-Verbal Behavior (NVB) to study their congruence. It can be done through specific protocols such as the NBAM or Nonverbal Behavior Analysis Protocol (López, Gordillo and Soto, 2016)), which can incorporate the FEAP (Facial Expression Analysis Protocol) and the Nonverbal Behavior Analysis Matrix (NBAM), of a preferential application when video recordings are available. (V2) 
- Verification (Correspondence, External Coherence, Context): Contrast of the information with objective and subjective elements of the context, obtained through research (criminalistics, private investigators, OSINT -Open-Source Intelligence-, etc). (V3)

It should be added whenever possible, better in a transversal way but, at least, as a specific phase, the Identity Valuation starting from the indirect personality profiling, which we will call Calibration or Valuation (V0) and in its simplest application would be based on Eysenck's PEN model (Gonzalez and Lopez, 2016). In its protocolized format, Indirect Personality Profiling (IPP) would be part of the Nonverbal Behavior Analysis Protocol.

SAVE can be represented by a formula; an equation oriented to clear the unknown, the element of Validity we are looking for in the case:

$$
\mathrm{X}=(\mathrm{V} 1+\mathrm{V} 2+\mathrm{V} 3) \mathrm{V} 0
$$

Thus, we represent the three basics SAVE phases as summands and V0 (Valuation of Identity) as a multiplicative factor of all of them. On the one hand, V1 and V2 are integrating the Interview Domain; on the other hand, V3 and V0 correspond to the Context and Identity Investigation Domain. The latter, like everything in SAVE, allows a very simplified application, for example, only with indirect personality profiling based on Extroversion and Neuroticism in the PEN Model.

Its possibilities are very wide, it is flexible, and it is always possible to simplify its application according to our circumstances and those of the case. It is possible, and sometimes even advisable, to apply the phases in a different order than the numerical one; for example, using V3 as the first SAVE action, reviewing the available contextual information to obtain previous references about the issues about which we will later obtain a statement (V1) through an interview together with its associated NVB (V2). Likewise, V0 is developed in a way that crosses the other phases, by inferring personality traits, intelligence, and entailments while analyzing areas of behavior, verbal, non-verbal, contextual, etc.

\section{CONCLUSIONS}

The SAVE Metaprotocol comprises a methodology based on knowledge, skills, and even attitudes obtained from various scientific fields. It integrates a wide set of tools of interdisciplinary origin that we consider useful to develop the investigative, expert, or forensic activity; that can be learned and applied habitually in daily practice.

We consider that its theoretical framework is Behavior Analysis, a field that justifies further deepening its knowledge and research to improve our performance. This work aims to encourage the 
exchange of opinions and we hope to have the contributions of interested colleagues to further develop the methodology of Behavior Analysis based on SAVE in which we have been working for some years.

Keywords: Behavioral analysis, testimony credibility, non-verbal behavior, deception detection, indirect personality profiling. 


\section{REFERENCES}

Domínguez-Muñoz, A., Gómez Álvarez, A., de la Fuente Madero, J., López Pérez, R., García Ruiz, P., \& López Pérez, R. (2017a). Opinions of medical inspectors about clinical distortion in the assessment of incapacity for work in Spain. Ars Medica-Revista de Ciencias Médicas, 42(1), 13-19.

Domínguez-Muñoz, A., De la Fuente, J. L., Gómez, A. M., García, P., López M. J., \& López, R. (2017b). Behavioral Analysis in Evaluative Medicine: an interdisciplinary proposal. Medicina y Seguridad en el Trabajo, 63(248), 260-275.

Domínguez-Muñoz, A, De la Fuente, J. L., Gómez, A. M., García, P., López M. J., \& López, R. (2018). SAVE-System for Validity Analysis in the Expert Medical Evaluation. In XII Jornadas de Valoración del Daño Corporal. Medical-practical aspects. (pp.245-260) Madrid: Fundación Mapfre.

González, J. L., and López, R. M. (2016). Personality and Behavior. Indirect Personality Profiling. In R. López, F. Gordillo, \& M. Grau (Eds.), Comportamiento no Verbal: más allá de la comunicación y el lenguaje. Madrid: Pirámide

Ilizástegui Dupuy, F., \& Rodríguez Rivera, L. (1990). The clinical method. Rev Finlay, 4(4), 3-23.

López, R. M., Gordillo, F., \& Soto, J. E. (2016). NBAM (Nonverbal Behavior Analysis Matrix) protocol. In R. López, F. Gordillo, \& M. Grau (Eds.), Comportamiento no Verbal: más allá de la comunicación y el lenguaje. Madrid: Pirámide.

López, R. M., Domínguez-Muñoz, A., Grau, M., Juárez, A., Jiménez, J., \& Garrido, M. J. (2018). SAVE metaprotocol for behavior analysis. An integrative proposal. In E. Arias, J. Sanmarco, \& X. Camplá (Eds.), XI International Congress of Legal and Forensic Psychology. (pp. 528-541). Granada: Spanish Society of Legal and Forensic Psychology.

Muñoz, J., Manzanero, A., Alcázar, M., González, J., Pérez, M., \& Yela, M. (2011). Legal Psychology in Spain: Conceptual Delimitation, Research and Intervention Fields and Training Proposal within the Official Teaching. Anuario de Psicología Jurídica, 21, 3-14.

Muñoz, J. (2013). The forensic psychological evaluation of psychological damage: proposal of a protocol of expert action. Anuario de Psicología Jurídica, 23, 61-69.

Nateras González, M. (2005). The importance of method in research. Espacios Públicos, 8 (15), 277-285. 